\title{
PINTER'IN KADINLARI
}

Araş. Gör. Dṛ. Selda ÖNDÜL

Yüzyılımızın tanınmış usta tiyatro adamlarından biri olan Harold Pinter 1957 ile 1981 yılları arasındaki oyun yazarlığı serüveni sürecinde yirmi tiyatro, radyo ve televizyon oyunu yazmıştır. Bu oyunlar tarih sirasiyla The Room (Oda), The Birthday Party (Doğum Günü Partisi), The Dumb Waiter (Git Gel Dolap), A Slight Ache (Ince Bir Siz1), A Night Out (Dişarıda Bir Gece), The Caretaker (Kapic1), Night School (Gece Okulu), The Dwarfs The Collection (Koleksiyon), The Lover '(Aş1k), Tea Party (Çay Partisi), The Homecoming (Eve Dönüş), The Basement (Bodrum), Landscape (Manzara), Silence (Sessizlik), Old Times (Eski Zamanlar), Monologue (Monolog), No Man's Land (Issiz Topraklar), Betrayal (İhanet) ve Family Voices (Aile Sesleri)'nden oluşmaktadır.

Pinter oyunlarında insanın evrendeki deneyimini elé alır. İnsan deneyimini acı olarak niteler. Insan evrende yapayalnızdır çünkü ne kendisi ile, ne de başkaları ile iletişim kuramaz. İletişim kurmak tehlikelidir. Insan gerçek yüzünü gösterdiğinde açık vermiş olacak ve kötücüllüğe karşı savunmasız kalacaktır. Bu yüzden de ne kendisini anlatır, ne de bir başkasının kendi dünyasına girmesine izin verir. Yüzünden maskesini eksik etmez.

Pinter, insanı bir savaş içinde algılar ve yansıtır. İnsan içini dışardakine açık etmez. Aynı zamanda kimliğinin ve varlığının doğrudan göstergesi olan odasını/ evini (mekanını) bir başkasına kaptırmamaya çabalar. Oda içinde hareketsiz, hapis ama güvendedir. Ancak, aynı nedenlerle, dışandaki de sürekli içeriye girmeye çalı̧tığından odanın kapısı açılır ve içerideḳi/ler ile dışarıdaki/ler arasında amansız bir savaşım başlar. Aslında dışarıdaki/ler her zaman bir kişi görünümünde gelmez. Dışarıdaki tehlike insanın maskesiz benliği, geçmişi veya adı belli olmayan bir tehdittir. Savaşım sonunda yenen ile yenilen belirlenirse de her zaman yenen ile yenilen 
arasında kesin bir sınır yoktur. Çünkü bu savaşım sonsuza dek sürecek ve kazanan ile kaybeden sürekli yer değiştirecektir. Başka bir deyişle, feleğin çarkı durmaksızın dönecektir. Bu savaşım esnasında ittifaklar kurulup bozulacak, herkes birbirini kandiracak, yeni stratejiler belirleyecek ve yaşam oyununu kuralına göre oynayacaktır. Varolma ritueli ise sürüp gidecektir..

Insanın alın yazısı asla değişmeyecektir. Tek değişmeyen değişmenin kendisidir. Saltık gerçek budur. Zaman süreci içinde gerçek, umut ifade etmez. Geçmiş ise huzur vermez. Insan halde tutukludur. $\mathrm{Hal}$, sürekli yerini geçmişe burakmakta ve karanlı geleceğe doğru dört nala akmaktadır.

Pinter insanı, özellikle de erkeği bu koşullar içinde ifade ederken onu kadın ile bir karşıtlık içinde ele almaktadır. Pinter'in ọunlarında erkek kahramanlar eziktir, kadınlar karşısında yeniktir.

Sophokles'in Kral Dedipus oyununun öyküsünü hepimiz biliriz: Oedipus babasını öldürüp annesi ile evlenir bilmeyerek, gerçeği öğrendiğinde de kendisini kör eder. Psikolojide bu söylence Oedipus kompleksine temel 'oluşturmuştur daha sonra. Pinter, oyunlarında bu temi adeta saplantısal olarak işlemekten kendini alamamıştır. Pinter'in erkekleri, kaba bir genelleme ile, annenin tutsak edici sevgisi sonucunda başka kadınları sevemeyen, onları salt iki biçimde, ya anne-eş ya da fahişe, ama her zaman kendisini ezecek olan bir güç olarak gören kişilerdir. Bu rolleri bazan tek bir kadın üstlenirken, bazan da iki ya da daha çok sayıda kadın aynı rolü oynayabiliyor. Pinter'ın, erkeği boğan üçgen ilişkiler örgüsü ise hiç değişmiyor.

Pinter'ın Oda, Doğum Günü Partisi, Ínce Bir Sızı, Dişarıda Bir Gece, Gece Okulu, Koleksiyon, Aşık, Çay Partisi, Eve Dönüiş, Bodrum, Manzara, Sessizlik, Eski Zamanlar, Monolog ve Issız Topraklar oyunlarını incelediğimizde kadınlar? bu iki rolde (anne-eş-fahişe) görüyoruz. Kadının anne-eş ve/veya fahişe olarak yansıtılması Doğum Günui Partisi, Ince Bir: Sızı, Dışarıda Bir Gece, Gece Okulu, Aşık, Çay Partisi ve Eve Dönüş adlı oyunlarda bir tema, bir örüntü oluştururken diğer oyunlarda motifden öteye gitmiyor. Bu nedenle sözkonusu altı oyunu ele almak yerinde olacaktur.

Pinter'ın ilk uzun oyunu Doğum Günü Partisi'nde Stanley Weber, kıstırılmışlığı ve korkuyu en uç noktada yaşamaktadır. S1- 
ğındığı pansiyondan dışanı çıkamamakta, sığındı ̆̆ı kadına tutsak olmaktan kendisini kurtaramamaktadır. Dı̧̧ dünyadan kaçmakta, korkuyla birilerinin kendisini almaya geleceği günü beklemektedir. Korkularının yersiz olmadığı iki insan avcısının, Goldberg vc McCaan'ın gelişi ile anlaşlır. Meg, tehlikeden habersiz Stanley için bir doğum günü partisi düzenler. Hediye olarak da ona oyuncak bir trampet alır. Eski bir konser piyanisti olan Stanley bir düşüş sürecinin son aşamasına gelmiştir. Partiye Goldberg, McCaan, Meg, işlevi komşu kız Lulu katılır. Körebe oynarlar. Gözleri bağlı olan Stanley tarampetinin üzerine basar, kırar. "Ana rahminin" güvenli ortamından ikinci bir kovuluştur bu. Meg'i boğmaya, Lulu'ya tecavüz etmeye kalkışır. Kendisine egemen olan güçlerden silkinme çabasırıdadır. Kadın cinsinin iki yüzünü simgeleyen Meg ile Lulu kạrşısında acizdir Stanley. Aynı zamanda da Meg'a kızgndır kendisini Goldberg ve McCaan'dan koruyamadığı için. Lulu'nun cinselliği de onu korkutmaktadır. Stanley hem anne, hem de fahişe olan'kadın karşısında güçsüzdür, iktidarsızdır. Gözleri iyi görmeyen Stanley'in gözlüklerinin kurılışı bu güçsüzlüğün göstergesi olur. Meg Stanley’in Goldberg ve McCaan tarafindan götürülmesini önleyemez. Hatta haberi bile yoktur olup bitenden. Stanley'in ölüme götürüldüğünün farkına varmaz. Ya da bilmezlikten gelir. Ancak geride egemenliğini kullanacağı bir başka erkek vardır: Petey; Meg tarafindan beslenip bakılacak, her zaman boyun eğecek, sessiz koca.

Dişarda Bir Gece oyunda Albert Stokes annesinin dizinin dibinden ayrılmadığı için arkadaşları arasında alay konusu olmuştur. Bir gece, çalış̧ı̆̆ şirketten ayrılan biri onuruna verilen bir partiye gitmek için güç bela evden çıkar, annesinin tüm sitemlerine karşın. Partide arkadaşları ona bir oyun oynarlar. Onu kızlardan birine çimdik atmakla suçlarlar. Yapmadığını söylerse de kimse inanmaz ona. Partiyi terkedip eve gelip de annesinin dırdırları ile karşılaşınca kendisini tutamaz, annesine el kaldırır, sonra da kendisini sokağa atar ve rastladığı ilk sokak kızının evine gider. Kızın, annesini anımsatan ezici tavrı karşısında umulmadık bir biçimde sertleşir ama kurtuluşu olmadığını anlayarak yine evine, annesine döner. Annesine el kaldırmasından ve sokak kızına karşı çıkışından sonıa evdeki güç dengesinin değişip değjşmeyeceği kesin olarak belli değildir. Oyun açık uçla biter: Önemli olan Pinter'in bir kez daha erkeği ezik olarak, kadını da anne-fahişe ikileminde yansıtmasıdır. Kadın, anne olarak da, karşı cins olarak da erkekten hep alan, onun erkeklik gücünü yok edendir. 
Çay Partisi'nde orta sinıftan gelme çok zengin ve nüfuzlu bir işadamı olan Disson'ın düşüşü yansıtılmıştır. Disson bir taraftan saygın bir mevki, bir taraftan da cinsel doyum aramaktadır. Evleneceği kadın Diana, özlediği saygınlığı ona sağlayacak, çocuklarına iyi bir üvey anne olacaktır ama cinsel doyum getirmeyecektir. Sekreteri Wendy ise kadının cinsel yönünü simgelemektedir. Geçici körlük nöbetleri sırasında Disson kayınbiraderi Willy'nin, aynı zamanda Diana ve Wendy ile seviştiğini düşler. Bu aslında Disson'ın kendi özlemidir. Çünkü anıcak bu iki kadın biraraya geldiklerinde eksiksiz bir kadını oluş̧turabilmektedirler. Pinter'ın, Disson'ı Dianá karşısında sosyal açıdan Wendy karşısında da cinsel açıdan güçsüz çizmesi, erkeğin "iktidars.zlı̆̆ın" simgelemektedir. Yazar gerek Doğum Günü Partisi'nde gerek Çay Partisi'nde, körlük motifini kullanarak Oedipus söylencesine göndermeler yapmıştrr.

Gece Okulu'nda Walter dokuz aylik bir mahkumiyet sonucunda evine döner. Ancak beraber oturduğu teyzeleri Annie ve Millie'nin odasını Sally'e kiraya verdiklerini öğrenir. Sally gündüzleri öğretmenlik yaptığını, geceleri de bir dil okuluna devam ettiğini söylemiştir. Bir gece yalnız kaldıklarında Sally Walter karşısında son derece rahat davranır, hatta davetkardır. Ama Walter ona el bile süremez. Sally'e sanki jimnastik yaptırıyormus gibi komutlar vererek ona üstünlük sağlamaya çalışır. Erkek gücünü bu yolla kanıtlayabileceğini düşünmektedir. Korkmuş gibidir. Daha sonra Sally'nin odasında bulduğu bir fotoğrafdan onun aslında geceleri dil öğrenmek için okula gitmediğini, konsomatrislik yapmak için bir gece klübünde çalıştığını anlar. Kimseye bir şey söylemez. Ev sahipleri, Solto'yu çaya davet ettikleri bir gün Walter ona bulduğu fotoğrafı gösterir ve kızın kim olduğunu açılamadan onu bulmasını ister. Solto kızı bir gece klübünde bulur, Walter adlı bir arkadaşının isteği üzerine kendisini bulduğunu söyler. Ertesi gün Sally evden ayrilacak, Solto Walter'a kızı bulamadığını söyleyecek, Walter da bu yanıtı hemen kabullenecektir. Sally öğretmen aldatmacasında da, fahişe konumunda, da Walter'dan üstündür. Walter'ın yapacağı tek şey anne rolünü üstlenmiş olan teyzelerine sığınmaktır.

\footnotetext{
Doğum Günü Partisi, Dişarıda Bir Gece, Çay Partisi ve Gece Okulu oyunları ile Ince Bir Sızı, Aşık ve Eve Dönüş̧ oyunları arasındaki ayrım birinci gruptaki oyunlarda anne ve fahişe rollerinin ayrı kadınlar tarafindan, ikinci gruptakilerde ise ayn kadinlar tarafindan oynanmasıdır. Gece Okulu'nda Sally'nin konso-
} 
matris olup ta öğretmen aldatmacasında karşımıza çıkması ve ănne rolünü Annie ve Millie'nin paylaşması oyunun bu iki grup arasında köprü görevini üstlenmesindedir. İkinci grúp oyunlar birinci gruba kıyasla daha yetkin ve kendine özgü artıları olan oyunlardır.

Ince Bir S1zı Oyununda Edward ve Flora'nın aylardır kapılarının önünde gece gündüz hiç ayrılmadan, hiç konuşmadan, yemeden içmeden duran esrarengiz kibritçi yüzünden rahatları kaçmıştır. Sonunda bir gün kibritçiyi eve getirirlér. Onunla konuşmaya çalışırlar. Ancak Edward'ın da Flora'nın da diyalog kurma çabaları boşunadır. Konuşmaları monologlardan öteye gidemez. Edward, kibritçiye gençliğinin coşkusu ve gücünü özlemle anlatırken. Flora gençliğinde duyumsadığı cinsel heyecanları açılar. Kibritçí Edward'in yapamadığını, yapmış, Flora'yı cinsel yönden uyarmış, Edward'ın ise kişiliğini yitirme sürecini hızlandırmıştır. Oyunun başında gözlerinde ince bir sızıdan şikayetçi olan Edward oyunun sonunda görme yeteneğini tümdèn yitirir. Bu hem erkekliğini hem de kişiliğini yitirmesini simgelemektedir. Edward kibrit tablasını alıp sokağa çıkarken Flora kibritçiyi Barnabas diye adlandınp eve ve yatağına davet eder. Oyunun başlangıcında marmelada konan eşek arısı nasıl hiç acınmadan kör edilmişse, oyunun sonunda da Flora duraksamaksızın, bencilce kocasının kişiliğini, varlığını hiçe sayar. $\mathrm{Bu}$ oyunda kadın her ne kadar kesin hatları ile fahişe ve anne rolleri ile gösterilmemişse de erkek ile gözünü kırpmadan oynayan bir güç olarak çizilmiştir. Aşık oyununda Sarah ve kocası Richard erotik fantazilerle yüklü bir zina oyunu oynarlar. Bu oyun içinde oyuna Sarah açısından bakacak olursak. Sarah kocası işe gittiğinde, öğleden sonraları aşığını eve alan kadını, kocası Richard ise aşığı, Max'i oynar. Sarah Richard ile olduğunda topuksuz ayakkabılar ve spor giysiler içindedir, Max ile buluştuğunda yüksek topuklu ayakkabılar ve seksi giysilere bürünür. Richard Richard olduğunda takım elbise giyer, kravat takar; Max rolünde ise süet ceket giyer, kravat takmaz. Bu buluşmalarda Sarah ve Richard/Max bir dizi erotik fantaziyi ritueller biçiminde oyunlaştırırlar. Bu oyuna Richard açısından baktığımızda Richard Richard'ı Sarah da bir sokak kadınını oynamaktadır. Evliliklerinin ilk gününden, yani 10 ylldan beri süregelen bu ilişkiyi bir öğleden sonra Richard/Max noktalamak istediğini söyler. Nedeni de Sarah'ın çok zayıflamıs olmasıdır. Eve Richard olarak geldiğinde de sokak kadınından ayrıldığını anlatır Sarah'ya. Onun da Max'den ayrilması gerektiğini söyler. Sonra da gider. 
dolaptan erotik ritüeller sırasinda çaldığı bongoyu alır. Sarah şaşırmışı Richard'ın oyunun kurallarını bczmasina ama şehvet dolu öğleden sonralarının günün saygın bölümüne kaymasina da pek ses çıkarmaz ve dilek gerçekleştirme' oyununu başka bir boyutta devam ettïmeye sessizce karar verirler.

Richard saygın bir ev kadını ve annenin kendisini doyuma ulaştırmadığını ve şehvet de aradığı dile getirir oyunda. Richard için kadın salt eş-anne olarak yetersizdir. Bu yüzden de iki kadını (eş -anne ve fahişe) tek bir kadında ama iki ayrı kişilik altında arar. Sarah hem eş-anne hem de fahişedir. Ancak bu oyunun diğer oyunlardan temel ayrımı Sarah'ın da aynı arayış içinde olmasıdır. O da saygınlık ve şehveti bir arada istemektedir ve bu iki özelliği de aynı kişilikte bağdaştıramamaktadır. Bu oyunda, çağcıl bir yaklaşımla, cinsel istek yalnızca erkeği değil her iki cinsi de tutsak edici bir güç olarak çizilmiştir.

Pinter, yukarıda örneklenen temi kuşkusuz en kapsamlı olarak Eve Dönüş ovununda işlemiştir. Yazında çok kullanılmış olan "eve dönüş" motifinden yola çıkmış yazar bu oyununda. Evin en büyük oğlu Teddy karısı Ruth'u babası, amcası ve erkek kardeşlerine tanıştırmak üzere felsefe hocalı̆̆ı yaptığı ABD'den İngiltere'ye, doğup büyüdüğü eve gelir. Ailesiṇi görmeyeli alti yıl olmuştur. Eski bir çıplak model olan karısın evlendikten sonra ailesine tanışırımaya firsat bulamamıştır daha önce. Babası Max, amcası Sam, kardeşleri Lenny ve Joey onları her gün görüşüyormuşcasına son derece heyecansız karşlarlar. Oyun ilerledikçe Max'in emekli bir kasap, Sam'in taksi şöförü, Lenny'nin muhabbet tellalı, Joey'nin de boksör olduğunu öğreniriz.' Max'in gençliğinde yakın arkadaşı McGregor ile yeraltı dünyasından olduğu, kadın ticareti dahil yasal olmayan bir çok işe bulaştı̆̆ anlaşılır. Sam taksisinin arka koltuğunu, Max ve McGregor için fahişeler ve müşterilerine vermiştir ve büyük bir olasılıkla şimdi de Lenny hesabına çalışmaktadır. Max'in ölmüş karısı, oğlanların annesi Jessie' in fahişe olduğu, Max'in onu pazarladığı, bir keresinde de McGregor ile Sam'in arabasının arka koltuğunda seviştiği ortaya çıar.

Böylesi bir aileye karısını tanıştırmak için Teddy'nin niye daha önce firsat bulamadığını tahmin etmek zor değil. Ancak niye şimdi geldiğini anlamak zor. Gelir gelmez, hemen eve dönmek isteyen Rurh için Lenny ile tanıştıktan sonıra geriye adım atmak söz konusu değildir. 
Kendisini Jessie yerine koymak isteyen ailenin isteklerini kendi kurallarına göre karşllayacaktır. Onların hesabına fahişelik yapacak, evi çekip çevirecek, anne, şefkati gösterecektir. Oyunun sonunda Teddy oğullarının yanına dönerken Ruth koltukta bir tahttaymış edasıyla ctururken Max dizlerinin üstünde bir öpücük dilenmektedir, Joey hemen Rúth'un yanında çömelmiştir, Lenny ayaktadır ama o da Ruth'un hemen yanıbaşındadir. Sam ise baygin yerde yatmaktadır. Ruth uzun süren bir savaşımı kazanmıstır. Ailenin erkeklerini parmağında oynatacaktır. Teddy karısını kaybetmiş midir yoksa ondan kurtulmuş mudur bèlli değildir. Ama kesin olan bir şey vạrdır: Çocukları annesiz kendisi de yalnız kalmışır.

Söz konusu oyunlarda Pinter insanı/erkeği adeta bir eşikte çizmiştir: ya dışarıdan içeriye girmeye çalışmaktadır 'ya da içeriden dışarıya çıkmamaya. Eşikteki erkek ne erkektir ne de çocuk. Anne çocuğu koruyamaz çünkü o dạ güçsüzdür. Kadının cinselliği erkeği ezer çünkü erkek iktidarsızdır. Anne (eş) de fahişe de erkeğe egemen olmak ister çünkü güçlü olmak için mekanave/veya bir insana ege men olmak şarttır. Eşikteki erkek ise kadın karşısında kaybetmeye adeta yazgilidir.

\section{Kaynakça}

Pinter, Harold.: Complete Works: One (The Room, The Dumb Waiter, A Slight Ache, A Night Out, The Black and White, The Examination) New York: Grove Press, Inc., 1978.

.: Complete Works: Two (The Caretaker, The Dwarfs, The Collection, The Lover, Night School, Revue Sketches: Trouble in the Works, The Black and White, Request Stop, Last To Go, Special Offer) New York: Grove Press, Inc., 1977. Complete Works: Three (The Homecoming, Landscape, Silence, The Basement, Revue Sketches: Night, That's All, That's Your Trouble, Interview, Applicant, Dialogue for Three, Tea Party) New York: Grove Press, Inc., 1978.

: Complete Works: Four (Old Times, NoMan's Land, Betrayal, Monologue, Family Voices) New York: Grove Press Inc., 1981.

Pinter, Harold .: Complete Works: One (The Room, The Dumb Waiter, A Slight Ache, A Night Out, The Black 
and White, The Examination) New York: Grove Press, Inc., 1978.

: Complete Works: Two (The Caretaker, The Dwarfs, The Collection, The Lover, Night School, Revue Sketches: Trouble in the Works, The Black and White, Request Stop, Last To Go, Special Offer) New York: Grove Press, Inc., 1977.

: Complete Works: Three (The Homecoming, Landscape, Silence, The Basement, Revue Sketches: Night, That's All, That's Your Trouble, Interview, Applicant, Dialogue for Three, Tea Party) New York: Grove Press, Inc., 1978.

: Complete Works: Four (Old Times, No Man's Land, Betrayal, Monologue, Family Voices) New York: Grove Press Inc., 1981. 